\title{
Open surgical repair of an abdominal aortic aneurysm in a renal transplant recipient
}

\author{
Ünal Aydın (D), Muhammed Bayram (D), Safa Göde (D), Mugisha Kyaruzi (D), Onur Şen (D) \\ Department of Cardiovascular Surgery, Mehmet Akif Ersoy Thoracic and Cardiovascular Surgery Training and Research Hospital, Istanbul, Turkey
}

\begin{abstract}
Abdominal aortic aneurysm (AAA) surgical repair in renal transplant recipients requires alternative techniques for the protection of the transplanted kidney against ischemia and reperfusion injury. In this report, we present a renal transplant recipient who underwent open surgical repair of an AAA. After aortic cross-clamping, cold Custodiol ${ }^{\circledR}$ solution was infused to the renal artery. Postoperative renal ultrasound showed normal parenchymal echo pattern, and biochemical markers of renal functions were found at normal levels.
\end{abstract}

Keywords: Abdominal aortic aneurysm, kidney transplantation, surgery.

Endovascular aneurysm repair (EVAR) of abdominal aortic aneurysms (AAAs) has gained popularity during the last two decades. ${ }^{[1]}$ However, endovascular interventions have certain limits and some cases need to be repaired only with open surgical techniques. Renal transplant recipients require a particular attention than regular patients due to the fragility of the transplanted kidney. It is of utmost importance to avoid ischemic and reperfusion injury to the transplanted kidney. Open surgical repair of AAA becomes a challenge in these cases. There are some maneuvers for the protection of the kidney and these can be classified in two sections: (i) perfusion of the organ and (ii) increasing the tolerance to ischemia. The first section contains axillofemoral bypass, aortoiliac shunt, atriofemoral bypass, and femorofemoral bypass with extracorporeal circulation. ${ }^{[2]}$ Topical cooling, cold perfusion of the kidney, and perfusion of the kidney with an organ-preserving solution are the other components of the second section. ${ }^{[3]}$

In this article, we present an alternative organpreserving method customized for the renal transplant recipients undergoing surgical reconstruction of AAAs.

\section{CASE REPORT}

A 54-year-old woman was referred to our clinic with a diagnosis of asymptomatic infrarenal AAA. She had hypertension with no other risk factors for atherosclerosis. She had a history of coronary angiography with non-critical lesions, which were recommended for medical follow-up. Six years ago, she underwent a renal transplant which was uneventful within this period with normal renal functions. Preoperative contrast-enhanced computed tomography (CT) showed a fusiform AAA extending from below the level of the renal arteries to the terminal abdominal aorta before the bifurcation segment, with a maximal diameter of $7.2 \mathrm{~cm}$. Initially, the patient was evaluated for an EVAR procedure. However, the aortic neck angulation was over $60^{\circ}$ and the diameter was $40 \mathrm{~mm}$, which are the exclusion criteria for EVAR (Figure 1). Subsequently, the patient was evaluated for open surgical repair rather than the fenestrated or chimney EVAR techniques. However, she had a transplanted kidney, the artery of which was anastomosed to the right common iliac artery. This was of concern, as cross-clamping of the aorta would cause ischemia to the transplanted kidney.

Received: September 04, 2020 Accepted: October 19, 2020 Published online: January 18, 2021

Correspondence: Ünal Aydın, MD. Mehmet Akif Ersoy Göğüs Kalp ve Damar Cerrahisi Eğitim ve Araştırma Hastanesi Kalp ve Damar Cerrahisi Kliniğii, 34303 Küçükçekmece, İstanbul, Türkiye. e-mail: unalaydin41@gmail.com 
In these circumstances, the operation plan was made and a midline laparotomy was performed. Then, the renal arteries, aneurysm sac, and iliac bifurcation were explored. The iliac arteries and artery of the transplanted kidney were not explored, due to adhesions. After heparin administration (100 U/kg), a proximal cross-clamp was placed to the abdominal aorta just below the renal arteries and a distal cross-clamp was placed at the origin of the left iliac artery. The aneurysm sac was opened and the first balloon catheter was placed to the right iliac bifurcation. Next, the organ-preserving solution (Custodiol $^{\circledR}$, Dr. Franz Köhler Chemie $\mathrm{GmbH}$, Bensheim, Germany) catheter was placed to the ostium of the right iliac artery and the transplanted kidney was perfused with Custodiol (Figures 2 and 3). The solution was administered at 5 to $8^{\circ} \mathrm{C}$ with $1.5 \mathrm{~mL} / \mathrm{g}$ kidney $/ \mathrm{min}$ perfusion rate and 90 to $110 \mathrm{mmHg}$ perfusion pressure. Following these procedures, a tube graft interposition with a Dacron graft was performed and the distal artery flow was re-established. The cross-clamping time was $90 \mathrm{~min}$ for the transplanted kidney. The postoperative course of this patient was uneventful, with a well-preserved renal function. Postoperative renal ultrasound was performed which revealed a normal parenchymal echo pattern and perfusion of

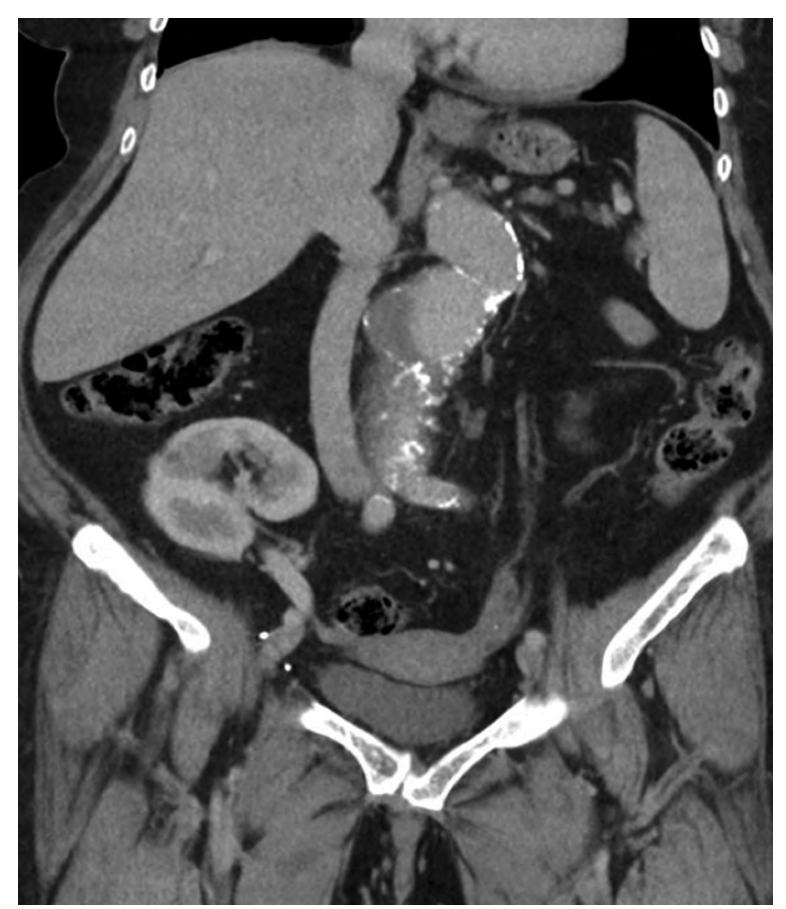

Figure 1. Computed tomography image of aneurysm and transplanted kidney. the kidneys. Postoperative biochemical markers of renal functions were also within the normal range. A written informed consent was obtained from the patient.

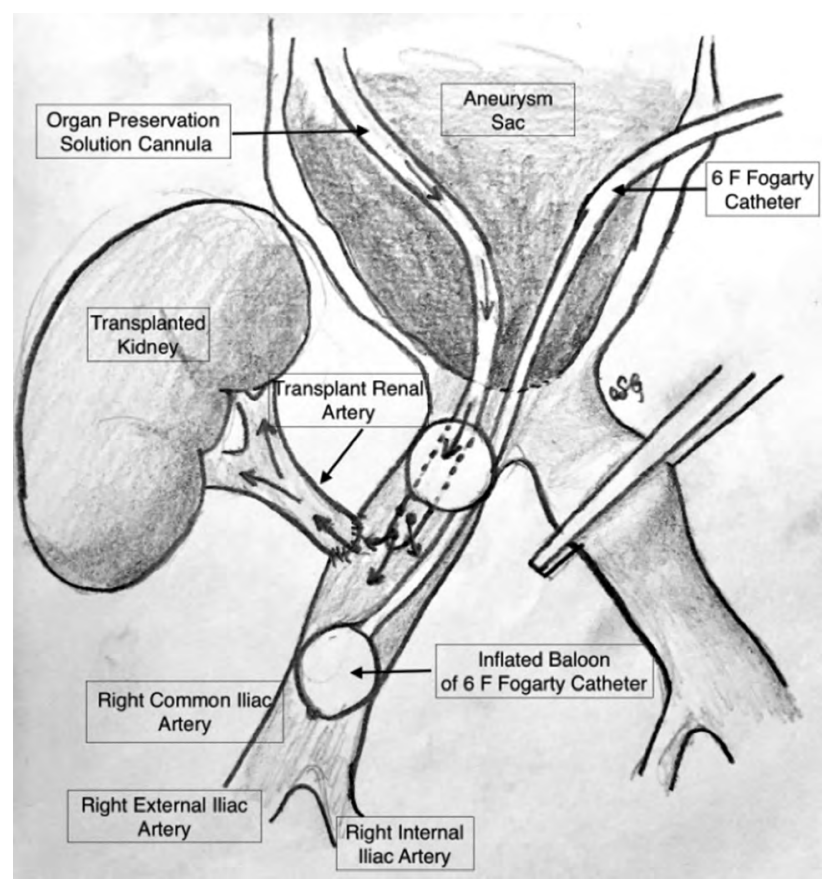

Figure 2. Illustration of surgical technique.

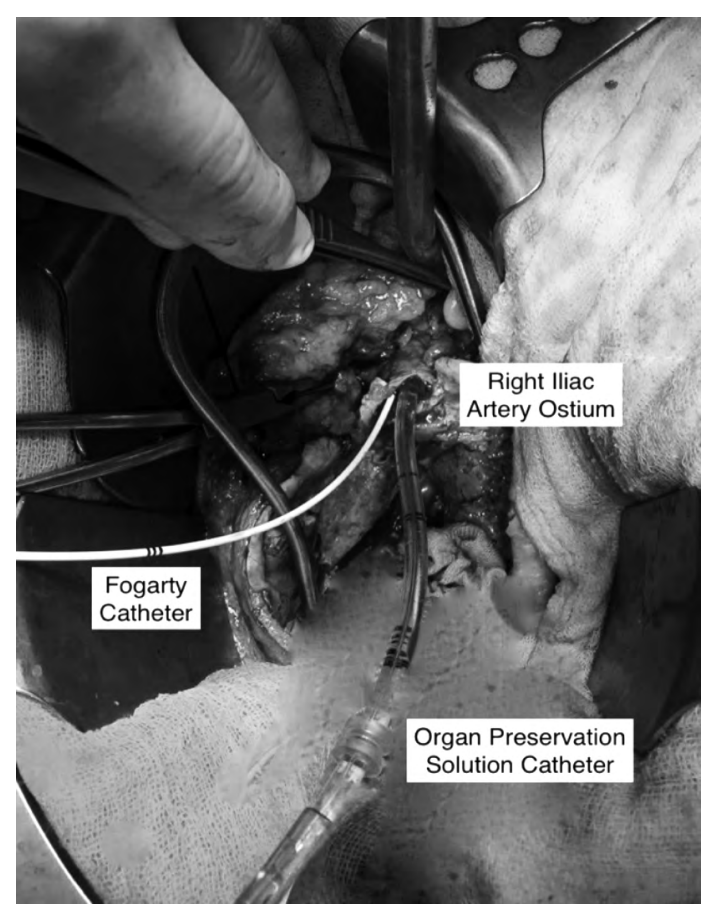

Figure 3. Peroperative exposure of aneurysm and perfusion catheters. 


\section{DISCUSSION}

Endovascular aneurysm repair is an alternative and safe procedure in the treatment of AAAs with a transplanted kidney. However, these patients are prone to vascular fragility due to the immunosuppressive drug use. ${ }^{[4]}$ Therefore, catheterization may provoke an iliac artery dissection, which can induce transplanted renal ischemia. In this case, EVAR via the left common femoral artery (CFA) and short limb connection from the left CFA would be the best route for stent-graft deployment. Consequently, in this case, the distance from the right iliac artery ostium to the renal artery anastomosis was not found to be sufficient for deployment (Figure 1). Furthermore, aneurysm progression and stent migration occurrence over time would cause renal artery occlusion and renal ischemia. Patients who are not good candidates for EVAR procedure must be treated with open surgical techniques.

In these cases, renal impairment is a challenging issue and various techniques have been improved to overcome this problem. Active or passive shunts between the femoral artery and aorta, axillary artery or contralateral femoral artery are such methods for perfusing the transplanted kidney retrogradely. ${ }^{[5]}$ These methods are used successfully in the management of AAAs with transplanted kidneys. However, we preferred none of them, as they are difficult to perform, and the increasing complexity of the surgery, particularly pump-supported perfusion, has the potential to induce a systemic inflammatory response.

Perfusion of a transplanted kidney with a cold solution through the common iliac artery seems preferable, since this method is the easiest method and does not excessively extend the surgical time. However, no consensus has been reached upon which solution should be preferred for perfusion, yet. Earlier, the Ringer's lactate was used by many departments for cold perfusion. ${ }^{[6]}$ Recently, Custodiol has been increasingly used for this purpose. It is a crystalloid solution with electrolyte concentrations similar to those of intracellular compounds. It also contains high concentrations of three main factors: (i) an amino acid buffering agent, histidine/histidine hydrochloride; (ii) the amino acid tryptophan $\alpha$-ketoglutarate, which supports membrane integrity; and (iii) the osmotic agent mannitol. ${ }^{[7]}$ This solution was previously used in unusual cases. ${ }^{[8]}$ Tshomba et al. ${ }^{[9]}$ compared renal perfusion solutions (Ringer's lactate versus Custodiol) during thoracoabdominal aortic aneurysm repair and found the freedom from acute kidney injury and estimated glomerular filtration rates to be significantly higher in the Custodiol group.

In conclusion, open surgical repair is still an important alternative in the treatment of AAA repair in kidney transplant recipients. Preoperative assessment and surgical planning are the main factors for managing aneurysms and protecting the kidney from ischemia and reperfusion. Renal perfusion with Custodiol is an effective and simple method for the preservation of the renal functions. It can be used in unusual cases with appropriate planning of organ perfusion.

\section{Declaration of conflicting interests}

The authors declared no conflicts of interest with respect to the authorship and/or publication of this article.

\section{Funding}

The authors received no financial support for the research and/or authorship of this article.

\section{REFERENCES}

1. England A, Mc Williams R. Endovascular aortic aneurysm repair (EVAR). Ulster Med J 2013;82:3-10.

2. Callaghan CJ, Munday IT, Casey ND, Large SR, Gaunt ME. Abdominal Aortic Aneurysm Repair in a Renal Transplant Recipient: A Modified Pump-oxygenation Bypass Technique to Reduce Hypotension and Myocardial Ischaemia. EJVES Extra 2005;10:120-1.

3. Moon IS, Park SC, Kim SN, Koh YB. Abdominal aortic aneurysm repair in kidney transplant recipients. Transplant Proc 2006;38:2022-4.

4. Tepperman E, Ramzy D, Prodger J, Sheshgiri R, Badiwala M, Ross H, et al. Surgical biology for the clinician: vascular effects of immunosuppression. Can J Surg 2010;53:57-63.

5. Sadat U, Huguet EL, Varty K. Abdominal aortic aneurysm surgery in renal, cardiac and hepatic transplant recipients. Eur J Vasc Endovasc Surg 2010;40:443-9.

6. Nghiem DD, Lee HM. In situ hypothermic preservation of a renal allograft during resection of abdominal aortic aneurysm. Am Surg 1982;48:237-8.

7. O'Callaghan JM, Knight SR, Morgan RD, Morris PJ. Preservation solutions for static cold storage of kidney allografts: a systematic review and meta-analysis. Am J Transplant 2012;12:896-906.

8. Tinelli G, Sica S, Minelli F, Natola M, De Nigris F, Tshomba Y. Horseshoe kidney protection with histidine-tryptophanketoglutarate solution during surgical abdominal aortic aneurysm repair. Ann Vasc Surg 2020;63:459.

9. Tshomba Y, Kahlberg A, Melissano G, Coppi G, Marone E, Ferrari D, et al. Comparison of renal perfusion solutions during thoracoabdominal aortic aneurysm repair. J Vasc Surg 2014;59:623-33. 